\title{
$\beta 1$-Integrin Alters Ependymal Stem Cell BMP Receptor Localization and Attenuates Astrogliosis after Spinal Cord Injury
}

\author{
Hilary A. North, Liuliu Pan, Tammy L. McGuire, Sarah Brooker, and John A. Kessler \\ Department of Neurology, Northwestern University Feinberg School of Medicine, Chicago, Illinois 60611
}

Astrogliosis after spinal cord injury (SCI) is a major impediment to functional recovery. More than half of new astrocytes generated after SCI are derived from ependymal zone stem cells (EZCs). We demonstrate that expression of $\beta 1$-integrin increases in EZCs following SCI in mice. Conditional knock-out of $\beta 1$-integrin increases GFAP expression and astrocytic differentiation by cultured EZCs without altering oligodendroglial or neuronal differentiation. Ablation of $\beta 1$-integrin from EZCs in vivo reduced the number of EZC progeny that continued to express stem cell markers after SCI, increased the proportion of EZC progeny that differentiated into GFAP + astrocytes, and diminished functional recovery. Loss of $\beta 1$-integrin increased SMAD1/5/8 and p38 signaling, suggesting activation of BMP signaling. Coimmunoprecipitation studies demonstrated that $\beta 1$-integrin directly interacts with the bone morphogenetic protein receptor subunits BMPR1a and BMPR1b. Ablation of $\beta 1$-integrin reduced overall levels of BMP receptors but significantly increased partitioning of BMPR1b into lipid rafts with increased SMAD1/5/8 and p38 signaling. Thus $\beta 1$-integrin expression by EZCs reduces movement of BMPR1b into lipid rafts, thereby limiting the known deleterious effects of BMPR1b signaling on glial scar formation after SCI.

Key words: astrocyte; BMP; integrin; neural stem cell; spinal cord injury

\section{Introduction}

Astrogliosis after spinal cord injury (SCI) involves both an early hypertrophic phase and a later hyperplastic phase (Fawcett and Asher, 1999; Barnabé-Heider and Frisén, 2008). The astrocytic hypertrophy is necessary for repairing the damaged blood-brain barrier, a beneficial process that limits inflammatory damage and restores homeostasis (Faulkner et al., 2004; Okada et al., 2006; Herrmann et al., 2008). However, the hyperplasia leads to formation of a dense glial scar that inhibits axonal regeneration (Fawcett and Asher, 1999; Silver and Miller, 2004). Because global interruption of gliosis has a negative effect on recovery from injury (Faulkner et al., 2004), therapeutic approaches must seek to alleviate the negative effects of astrogliosis, largely those caused by hyperplasia, while maintaining the earlier hypertrophy.

Ependymal cells (EZCs) surrounding the central canal in the adult spinal cord are stem cells capable of recruitment into cell cycle and multilineage differentiation following SCI (BarnabéHeider et al., 2010). By 4 months after SCI, $\sim 50 \%$ of new astrocytes have been generated from EZCs, while the remainder have derived from proliferation of existing astrocytes (Barnabé-Heider et al.,

\footnotetext{
Received Nov. 3, 2014; revised Dec. 19, 2014; accepted Jan. 8, 2015.

Author contributions: H.A.N., L.P., and J.A.K. designed research;H.A.N., L.P., T.L.M., and S.B. performed research; J.A.K. contributed unpublished reagents/analytic tools; H.A.N. and J.A.K. analyzed data; J.A.K. wrote the paper.

This work was supported by funds from the Craig H. Neilsen Foundation award 190465 and National Institutes of Health grants R01 NS20778 and R01 EB003806.

The authors declare no competing financial interests.

Correspondence should be addressed to Hilary A. North, 303 East Chicago Avenue, Ward 10-258, Chicago, IL, 60611. E-mail:h.north.scheler@northwestern.edu.

DOI:10.1523/JNEUROSCI.4546-14.2015

Copyright $\odot 2015$ the authors $\quad 0270-6474 / 15 / 353725-09 \$ 15.00 / 0$
}

2010). EZCs are therefore responsible for generating a significant portion of astrocytes populating the glial scar following SCI and are a promising target for therapeutic intervention.

Astrocytic hypertrophy and hyperplasia after SCI are regulated by different molecular pathways (Okada et al., 2006; Herrmann et al., 2008). For example, signaling by the BMPR1a subunit promotes astrocytic hypertrophy whereas BMPR1b signaling plays a role in hyperplastic glial scar progression (Sahni et al., 2010). However, the precise molecular mechanisms that regulate different phases of astrogliosis are not known. Since ECMinteracting proteins have been implicated in regulating both maintenance of the stem cell state and gliosis (McGraw et al., 2001; Kazanis and ffrench-Constant, 2011), we focused on the role of one such protein, $\beta 1$-integrin, in the response of EZCs to SCI. Our findings identify a novel mechanism of interaction between this molecule and members of the BMPR family that regulates EZC differentiation into GFAP-expressing astrocytes.

\section{Materials and Methods}

Transgenic mice. FoxJ1CreER mice (Rawlins et al., 2007) on a yellow fluorescent protein Cre-reporter background (RosaYFP; The Jackson Laboratory) backcrossed to C57BL/ 6 were also bred to $\beta 1$-integrin ${ }^{\text {flx/flx }}$ mice (The Jackson Laboratory) and studied beginning at age 8 weeks, \pm 5 d. Mice used were of either sex, and genders were evenly distributed across both genotype groups. Recombination was induced by five daily intraperitoneal injections of $30 \mathrm{mg} / \mathrm{ml}$ tamoxifen (Sigma) in 1:9 ethanol: corn oil, $180 \mathrm{mg} / \mathrm{kg}$.

SCI and behavioral analysis. All animal procedures were performed in accordance with the Public Health Service Policy on Humane Care and Use of Laboratory Animals and all procedures were approved by the Northwestern University Institutional Animal Care and Use Committee. 
Mice were anesthetized by inhalation with $2.5 \%$ isoflurane in $100 \%$ oxygen using VetEquip rodent anesthesia equipment. Incisions were made to expose the vertebral column, and laminectomies performed at spinal segment T11. SCIs were produced using the Precision IH Impactor, model 0400, with a $1.25 \mathrm{~mm}$ impactor tip, force of $55 \mathrm{kdyn}$ and dwell time of $60 \mathrm{~s}$. Following SCI, the skin was sutured (Autoclips, $9 \mathrm{~mm}$; BD Biosciences), and the animals were allowed to recover from anesthesia on a heating pad. Buprenex ( $2.5 \mathrm{mg} / \mathrm{kg}$, s.c.) and Baytril ( $5 \mathrm{mg} / \mathrm{kg}$, s.c.) were administered to minimize discomfort and infection. Bladders were manually expressed twice daily. A $5 \mathrm{~d}$ Baytril treatment course $(5 \mathrm{mg} / \mathrm{kg}$ daily, s.c.) was started in the event of hematuria. Behavioral analysis was performed according to a modified Basso, Beattie, and Bresnahan (BBB) hindlimb scale for mice (Joshi and Fehlings, 2002). Any mice not scoring 0 (for each hindlimb) $1 \mathrm{~d}$ post SCI were excluded from the behavioral analysis, and any mice not displaying tamoxifen-induced recombination (as per YFP expression in the spinal cord) were retroactively excluded from the behavioral cohort.

Immunohistochemistry. Mice were killed by $\mathrm{CO}_{2}$ inhalation and perfused transcardially with HBSS and then $4 \%$ paraformaldehyde (Sigma) in PBS, pH 7.4. Spinal cords were dissected and removed, postfixed in paraformaldehyde for $2 \mathrm{~h}$, washed in PBS, and cryoprotected in 30\% sucrose in PBS overnight. Spinal cords were then frozen in Tissue-Tek embedding compound and $50 \mu \mathrm{m}$ sections were generated using a Leica CM3050S cryostat. Tissue sections, mounted onto SuperFrost Plus microscope slides, were incubated in blocking buffer $(10 \%$ Normal Swine Serum in PBS with $0.01 \%$ Triton X-100) for $1 \mathrm{~h}$ followed by primary antibody (see below, Antibodies, for sources and dilutions) diluted in $10 \%$ blocking buffer in PBS. Primary antibody incubation proceeded overnight at room temperature, and following washes in PBS, secondary antibodies (see below, Antibodies) were applied for $1 \mathrm{~h}$ at room temperature. Sections were again washed in PBS and mounted underneath coverslips using Prolong Gold hardening mounting reagent (Cell Signaling Technology).

Neural stem cell cultures. $\beta 1$-integrin ${ }^{\text {flx/flx }}$ or ${ }^{+/+}$mice were killed on P1 and either spinal cords, for EZCs (Meletis et al., 2008), or cortical subventricular zones (Mehler et al., 2000) were isolated. Cells were manually dissociated and plated into neural stem cell media: DMEM/F12 (Gibco) with B27, N2, Pen/strep/glutamine, and EGF (20 ng/ml; human recombinant; BD). EZC culture media contained, in addition, $10 \mathrm{ng} / \mathrm{ml}$ bFGF and heparin. Cultures were passaged every $4 \mathrm{~d}$. After passage 1, cultures from pups of the same genotype were combined at 50,000 cells/ $\mathrm{ml}$. After passage 2, cultures were infected with adeno-cre virus $(0.1$ $\mu \mathrm{l} / \mathrm{ml}$; ViraQuest). After passage 3, dissociated cells were plated either in suspension again (for harvest after an additional $4 \mathrm{~d}$ in neurosphere form) or plated at $1 \times 10^{4}$ cells $/ \mathrm{cm}^{2}$ in adhesion conditions (Neurosphere media containing $0.5 \mathrm{ng} / \mathrm{ml} \mathrm{EGF}$, for $7 \mathrm{~d}$ ) on coverslips or TC flasks coated with 1:50 PDL (Sigma) in water followed by 1:50 laminin (Roche) in PBS. Cells treated with BMP received 2-20 ng/ml BMP4 in the culture media beginning $24 \mathrm{~h}$ after plating, such that BMP was present for $6 \mathrm{~d}$ before harvesting. Cells treated with noggin received $250 \mathrm{ng} / \mathrm{ml}$ on the same time course. "Mosaic" cultures were obtained using these same methods, with $\beta 1$-integrin ${ }^{+/+}$and $\beta 1$-integrin ${ }^{\text {flx/flx }}$ neural stem cells (NSCs) or EZCs combined 1:1 at the final passage before plating for differentiation.

Cell preparation and Western blot. Adherent NSC cultures, having differentiated for $7 \mathrm{~d}$, were treated with trypsin-EDTA (2.5\%, Invitrogen) and harvested manually from TC flask surfaces. The trypsinized differentiated NSCs or the NSCs harvested from suspension were collected by centrifugation, washed in PBS, and lysed in T-PER (Pierce) with Halt proteinase-phosphatase inhibitor (Pierce) on ice for $15 \mathrm{~min}$ with intermittent vortexing, centrifuged at $15,000 \mathrm{~g}$ for $20 \mathrm{~min}$, and the resulting supernatant was saved for Western blot analysis. Lipid raft signaling fractions were isolated from cell pellets, harvested as described above, using the ReadyPrep Protein Extraction system (Signal; Bio-Rad). Western blot analysis was performed on whole-cell or lipid raft fraction samples after resolution on SDS-PAGE and transfer onto nitrocellulose membranes (Bio-Rad). Membranes were incubated in 5\% Blotto (Santa Cruz Biotechnology) in TBS with 1\% Tween 20 for $1 \mathrm{~h}$ at room temperature, followed by primary antibody incubation in the same blocking buffer (see below, Antibodies, for their concentrations) overnight at 4C. Membranes were then washed in TBST, incubated in secondary antibody for $1 \mathrm{~h}$ at room temperature, and washed again in TBST. Detection was performed using SuperSignal West Femto Maximum Sensitivity Substrate detection system (Pierce). Immunoblots were stripped and reprobed using Restore Western Blot Stripping Buffer (Pierce).

Antibodies. Primary antibodies used and their dilutions for immunohistochemistry (IHC), immunocytochemistry (ICC), or Western blot (WB) are as follows: rabbit $\alpha$-GFP (Abcam; IHC 1:1000); chick $\alpha$-GFP (Abcam; IHC 1:2000); rat $\alpha$ - $\beta 1$-integrin (Millipore; IHC/ICC 1:500, WB 1:1000); mouse $\alpha$-APC (Cal Biochem; ICC 1:500); mouse $\alpha$-Map2 (Abcam; ICC 1:500); mouse $\alpha$-NeuN (Millipore; ICC 1:500); mouse $\alpha$-nestin (BD; IHC 1:500); chick $\alpha$-vimentin (Millipore; IHC 1:1000); rabbit $\alpha$-GFAP (Dako; IHC/ICC 1:1000, WB 1:5000); rabbit $\alpha$-pSMAD1/5/8 (Cell Signaling Technology; IHC/WB 1:500); rabbit $\alpha$-pp38 (Cell Signaling Technology; WB 1:500); rabbit $\alpha$-ID1, 2, 3, and 4 (Santa Cruz Biotechnology; WB 1:500); mouse $\alpha$-GAPDH (Millipore; WB 1:5000); rabbit $\alpha$-BMPR1a (Santa Cruz Biotechnology; WB 1:1000); rabbit a-BMPR1b (Millipore; WB 1:500); and rabbit $\alpha$-Flotillin (Sigma; WB 1:500. Secondary antibodies used in IHC/ ICC were Alexa 647 (infrared), Alexa 555/594 (red), and Alexa 488 (green)conjugated secondary antibodies (Invitrogen; all 1:1000). DAPI was used at 1:5000. Secondary antibodies used in WB were HRP-conjugated secondary antibodies (Santa Cruz Biotechnology; 1:1000).

Image acquisition and analysis. All fluorescent images were acquired using a Leica TCS SP5 MP confocal microscope (Fixed Stage System DM6000 CFS); an IR-CCD camera; LAS AG software; and 20×, 40×, or $63 \times$ objectives at room temperature through Prolong Gold hardening sample mounting medium (Cell Signaling Technology). Images were acquired using sequential scanning of channels to prevent false positive appearance of colocalization of two antibodies. Images were processed in ImageJ and Photoshop. Differentiated cell cultures were analyzed by counting cells positive for GFAP, Map2, NeuN, or APC, while ICC for $\beta 1$-integrin was performed in parallel to confirm its successful ablation. Mosaic cultures were subjected to ICC for both $\beta 1$-integrin and GFAP on the same coverslips, and the $\beta 1$-integrin-null cells neighboring $\beta 1$ integrin-expressing cells were analyzed for GFAP expression. For In vivo experiments, $z$-stacks of equivalent thickness $(30 \mu \mathrm{M})$ were obtained from multiple (four to eight) fields surrounding the lesion site (as indicated in Fig. $3 c$ ) or in the area immediately surrounding (within $\sim 100$ $\mu \mathrm{M}$ of) the EZ (for Fig. 4). Such images were obtained from at least three separate tissue sections from each animal. In all cases, colocalization was determined and tracked on a cell-by-cell basis by an experimenter blinded to the genotype and/or treatment condition.

Statistical analyses. Significance scores were determined using Student's $t$ test or ANOVA using GraphPad software. All experiments culminating in Western blot were performed multiple times, quantified using Adobe Photoshop, and subjected to statistical analysis. All experiments culminating in immunohistochemistry or immunocytochemistry were performed multiple times (at least three experiments of $>500$ cells scored per experiment for in vitro studies and five experiments of $>500$ recombined cells scored per experiment for in vivo studies), quantified from images acquired on the microscope described above, and subjected to statistical analysis. For in vitro studies, each of the three experiments utilized distinct animals, though the cells within each experiment were pooled from multiple animals of the same genotype. For in vivo studies, 40 mice were included in the analyses in total over five experimental groups.

\section{Results}

\section{$\boldsymbol{\beta} 1$-integrin is robustly upregulated in ependymal cells following SCI}

We first examined the expression pattern of $\beta 1$-integrin in the injured spinal cord. After injury, there was a robust increase in $\beta 1$-integrin expression in cells surrounding the central canal (Fig. 1). To visualize changes in individual EZCs after injury, we bred FoxJ1creER mice, a tamoxifen-inducible line that expresses cre recombinase in spinal cord ependymal cells (Meletis et al., 2008), to a RosaYFP reporter line and induced recombination with $5 \mathrm{~d}$ of tamoxifen administration followed by $5 \mathrm{~d}$ of clearance before 


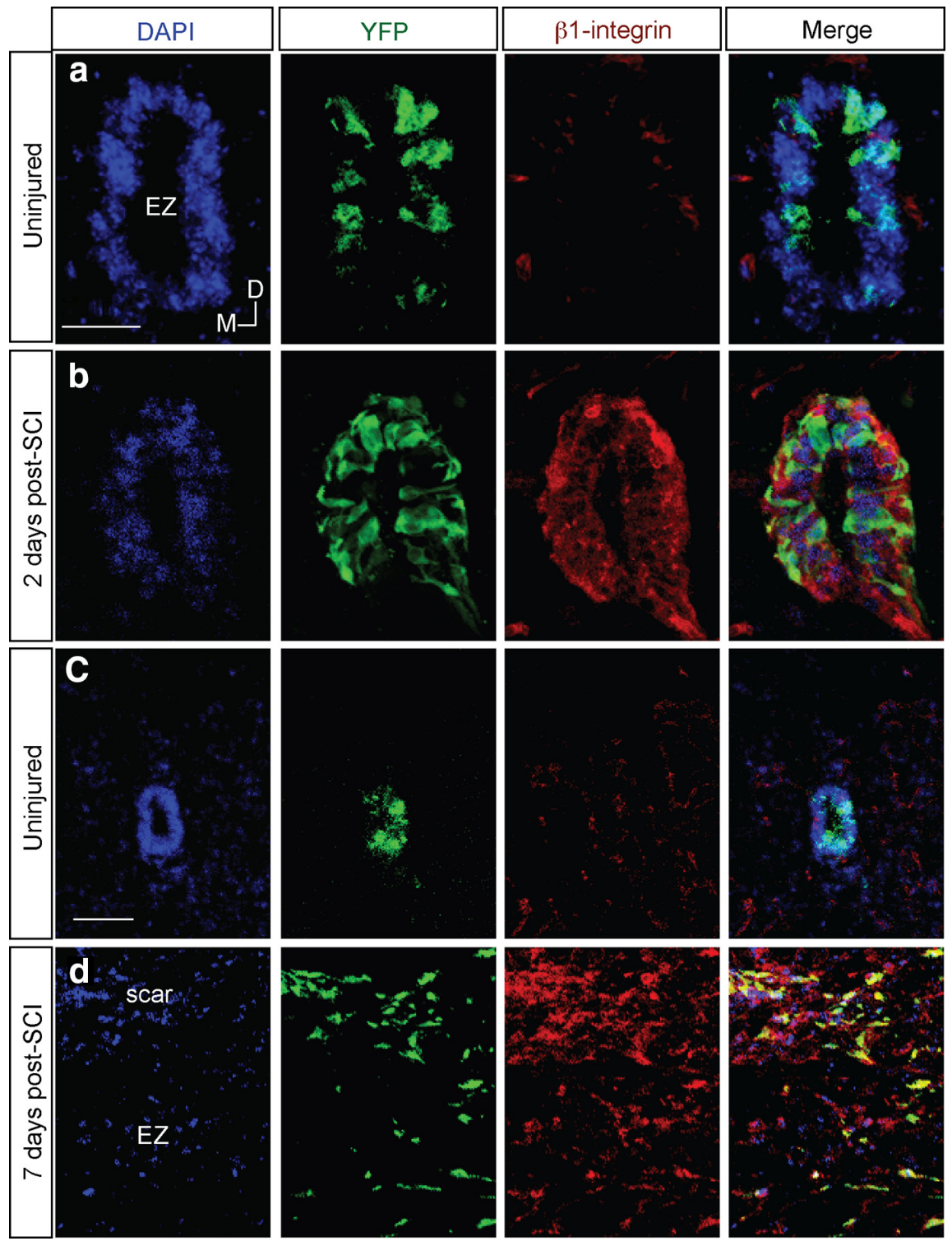

Figure 1. $\quad \beta 1$-integrin is robustly upregulated in ependymal zone cells following SCl. $\boldsymbol{a}-\boldsymbol{d}, \mathrm{DAPI}$ (blue),YFP (green), and $\beta 1$-integrin (red) expression in adult spinal cord. $\boldsymbol{a}$, EZ of intact spinal cord of FoxJ1creER; RosaYFP mice. YFP expression in the EZ has been induced by tamoxifen administration to FoxJ1creER mice. $\beta 1$-integrin expression is detected at low levels. $\boldsymbol{b}$, EZ of Fox J1creER; RosaYFP mice $2 \mathrm{~d}$ following SCI. $\beta 1$-integrin is significantly upregulated in EZ cells $2 \mathrm{~d}$ after SCl. $\boldsymbol{c}, \boldsymbol{d}$, Lower magnification images demonstrate migration of the $\mathrm{EZ}$ cells, which were recombined before $\mathrm{SCl}(\boldsymbol{c})$, away from the EZ by $7 \mathrm{~d}$ post $\mathrm{SCl}$ (d). Many of these cells, and others, continue to express $\beta 1$-integrin (yellow). Scale bars: $\boldsymbol{a}, 25 \mu \mathrm{m} ; \boldsymbol{c}, 50 \mu \mathrm{m}$. M, medial; D, dorsal.

injuring the spinal cord. In uninjured spinal cords, all FoxJ1cre recombined cells resided in the EZ surrounding the central canal. By $2 \mathrm{~d}$ post injury the number of $\mathrm{YFP}^{+}$cells in the EZ was increased, consistent with previous reports (Barnabé-Heider et al., 2010), and some $\mathrm{YFP}^{+}$cells had begun to migrate away from the EZ. A marked increase in $\beta 1$-integrin expression was evident in the EZCs compared with those in the uninjured condition (Fig. $1 a, b)$. By 7 d post injury, many $\mathrm{YFP}^{+}$cells had moved throughout the gray matter and lesion area, and $\beta 1$-integrin expression overlapped with the recombined cell distribution (Fig. 1c,d).

\section{$\beta 1$-integrin ablation from differentiating stem cells increases GFAP expression}

To define the role of $\beta 1$-integrin in differentiating EZCs, we examined the effects of cre-lox-inducible deletion of $\beta 1$-integrin in cultured postnatal EZCs from $\beta 1$-integrin ${ }^{\text {flx/flx }}$ mice. The cells were plated onto laminin-coated tissue culture dishes or coverslips in differentiating conditions and analyzed immunohistochemically (Fig. $2 a-f$ ) for GFAP (astrocytes; Fig. 2c,d), Map2 (neurons; Fig. 2e,f), or APC (oligodendrocyte precursors; Fig. $2 e^{\prime}, f^{\prime}$ ) expression after $7 \mathrm{~d}$ in vitro. $\beta 1$-integrinnull EZCs differentiated into GFAPexpressing astrocytes significantly more frequently $(49 \pm 3 \%)$ than wild-type cells $(27 \pm 2 \%$; $p<0.01$; Fig. $2 g)$. In contrast, deletion of $\beta 1$-integrin did not alter either neuronal or oligodendroglial lineage commitment. We performed identical experiments with NSCs cultured from the SVZ of postnatal mouse brain with similar results: deletion of $\beta 1$-integrin significantly enhanced astrocyte differentiation without altering neuronal or oligodendroglial differentiation (Fig. $2 h$ ). Analysis of $\beta 1$-integrin and GFAP coexpression in mosaic cultures, cultures in which some cells retained $\beta 1$-integrin expression while the protein was ablated in others, revealed that GFAP is elevated in cells lacking $\beta 1$-integrin even when those cells are interspersed with $\beta 1$-integrinexpressing cells (Fig. $2 i-i^{\prime \prime}$ ). This observation suggests that the $\beta 1$-integrin effect on astrogliosis may be cell autonomous. Together, these findings indicate that deletion of $\beta 1$-integrin promotes GFAP expression and astrocytic differentiation by both ependymal and SVZ stem cells in vitro.

We next sought to determine whether $\beta 1$-integrin plays a role in astrocytic differentiation of EZCs in vivo following SCI. To address this question, we mated $\beta 1$ integrin $^{\text {flx/flx }}$ and FoxJ1creER; RosaYFP mice and then mated the progeny to generate FoxJ1creER; RosaYFP; $\beta 1$-integ$\operatorname{rin}^{+/+}\left(\beta 1^{+/+}\right)$or FoxJ1creER; RosaYFP; $\beta 1$-integrin flx/flx $\left(\beta 1^{\mathrm{flx} / \mathrm{flx}}\right)$ littermates for use in SCI studies (Fig. 3a). Animals, aged 2 months, received tamoxifen for $5 \mathrm{~d}$, and an additional $5 \mathrm{~d}$ elapsed to allow for clearing of the drug before the SCI. Following a severe contusion injury, mice were killed $2 \mathrm{~d}, 1$ week, or 6 weeks later and their spinal cords were examined immunohistochemically (Fig. $3 b, c)$.

Consistent with previous reports, we found that vimentin, one marker for ependymal cells (Barnabé-Heider et al., 2010), was still expressed in the ependymal zone of both $\beta 1^{+/+}$and $\beta 1^{\mathrm{flx} / \mathrm{flx}}$ mice 6 weeks following injury (Fig. $3 d, e$ ). But while there were still many recombined $\left(\mathrm{YFP}^{+}\right.$) cells in $\mathrm{EZ}$ of the $\beta 1^{+/+}$mice (Fig. $3 d$ ), only a few such cells were present in the $\beta 1^{\mathrm{flx} / \mathrm{flx}}$ mice (Fig. $3 e$ ), indicating that virtually all of these cells had migrated out of the ependymal area. We also examined expression of the stem cell marker nestin and its coexpression with YFP in the glial scar region in $\beta 1^{+/+}$and $\beta 1^{\text {flx/flx }}$ mice to assess the relative stem cell states of ependymal progeny that had migrated into the lesion (Fig. $3 f, g$ ). A significant portion of YFP-expressing cells in the scar region expressed nestin in wild-type mice (Fig. $3 f$ ) indicating 
that the cells remained undifferentiated. In contrast, in cells lacking $\beta 1$-integrin (Fig. $3 g$ ), significantly fewer $\mathrm{YFP}^{+}$cells coexpressed nestin (Fig. 3h), suggesting that the cells had differentiated. Likewise, the proportion of EZC progeny in the area of injury that continued to express vimentin was also significantly reduced in $\beta 1^{\mathrm{flx} / \mathrm{flx}}$ mice (30 $\pm 4 \%)$ when compared with $\beta 1^{+/+}$animals $(57 \pm 6 \%$; Fig. $3 h)$. Vimentin expression was correspondingly reduced in $\beta 1^{\text {flx/flx }}$ cells differentiated in vitro (Fig. $3 i)$. Thus ablation of $\beta 1$-integrin enhanced migration of EZCs and their progeny from the ependymal region, and reduced the percentage of these cells that retained stem cell traits.

This suggested that there was increased migration of the EZCs into the lesion area with increased astrocytic differentiation as would be predicted by the culture studies and our previously published findings (Pan et al., 2014). Indeed, we found that $\mathrm{YFP}^{+}$cells in $\beta 1^{\text {flx/flx }}$ animals were more densely populated within the glial scar region than in $\beta 1^{+/+}$mice. A significantly $(p<0.01)$ increased proportion of the $\mathrm{YFP}^{+}$cells in the $\beta 1^{\mathrm{flx} / \mathrm{flx}}$ mice expressed GFAP compared with $\beta 1^{+/+}$mice (Fig. $3 j$, quantification in $k$ ). Thus ablation of $\beta 1$-integrin increased the generation of astrocytes in the lesion area by enhancing migration of cells from the ependymal zone, decreasing their stem cell properties and increasing GFAP expression within the cells.

Since glial scar formation is a major impediment to functional recovery after SCI (Fawcett and Asher, 1999; Silver and Miller, 2004), we asked whether the increased generation of astrocytes after ablation of $\beta 1$-integrin was associated with altered behavioral recovery. We performed open-field testing of $\beta 1^{+/+}$and $\beta 1^{\text {flx/flx }}$ mice for 6 weeks following SCI. By 6 weeks post injury, mice tend to display a modest amount of functional recovery without therapeutic intervention (Joshi and Fehlings, 2002). In fact, $\beta 1^{+/+}$control mice recovered from severe contusion injuries to an average of nearly 4 on the BBB scale (Fig. $3 l$ ). However, $\beta 1^{\mathrm{flx} / \mathrm{flx}}$ mice, whose ependymal cells lacked $\beta 1$-integrin at the time of SCI and during the recovery period, had significantly reduced behavioral recovery after the SCI (BBB score of $1, p<0.001$ ). Thus $\beta 1$-integrin expression by ependymal cells is important for functional recovery on following SCI.

\section{$\beta 1$-integrin ablation affects BMPR signaling in affected stem cells}

We next sought to define the molecular mechanisms underlying the effects of $\beta 1$-integrin expression by EZCs on astrocytic differentiation. BMP signaling, which increases following SCI (Setoguchi et al., 2001; Chen et al., 2005; Fuller et al., 2007), influences both the beneficial effects of reactive gliosis after SCI and the detrimental astrocytic hyperplasia that leads to formation of the glial scar (Setoguchi et al., 2004; Enzmann et al., 2005; Matsuura et al., 2008). The beneficial effects of BMP signaling are mediated
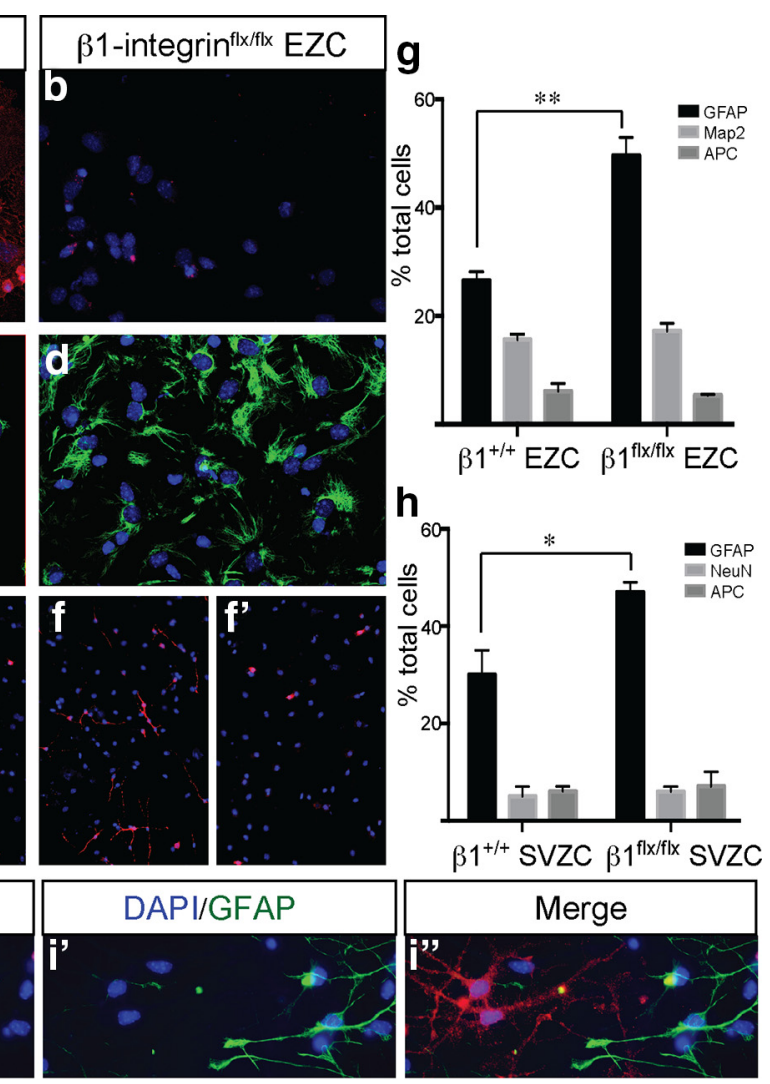

Figure 2. Deletion of $\beta 1$-integrin from spinal cord and SVZ-derived NSCs increases GFAP expression in differentiated cells. $\boldsymbol{a}-\boldsymbol{f}$, Intact $(\boldsymbol{a})$ and ablated $(\boldsymbol{b})$ expression of $\beta 1$-integrin (red) in adeno-cre-infected spinal cord EZCs derived from $\beta 1$-integrin ${ }^{+/+}(\boldsymbol{a})$ and ${ }^{\mathrm{fl} / \mathrm{flx}}(\boldsymbol{b})$ mice. GFAP expression (green) is significantly elevated in $\beta 1$-null (d) differentiated cultures compared with $\beta 1$ ineage cells. $\boldsymbol{i}-\boldsymbol{i}^{\prime \prime}$, In mosaic cultures containing both $\beta 1$-integrin (red)-expressing and $\beta 1$-integrin-null cells, GFAP expression (green) was present in a complementary fashion. Scale bars: $50 \mu \mathrm{m}$.

by the BMPR1a receptor, whereas the effects on astrocytic hyperplasia are mediated by BMPR1b signaling (Sahni et al., 2010). Interactions between TGF- $\beta$ signaling pathways, including BMP signaling, and the integrin family of receptors regulate a variety of physiologic processes in many organ systems (Wipff and Hinz, 2008; Munger and Sheppard, 2011). We therefore investigated the possibility that $\beta 1$-integrin exerts effects on astrogliosis by interacting with the BMP family of receptors.

BMPRs signal though phosphorylation and nuclear translocation of SMADs1/5/8 (Heldin et al., 1997). We first asked whether there was a change in phospho-SMAD1/5/8 (pSMAD1/5/8) expression by $\mathrm{YFP}^{+}$cells that had migrated out of the ependymal zone in $\beta 1^{\mathrm{flx} / \mathrm{flx}}$ mice compared with controls $\left(\beta 1^{+/+}\right)$. At $2 \mathrm{~d}$ following SCI, a significantly $(p<0.01)$ greater proportion of the $\beta 1^{\text {flx/flx }}$ cell population expressed nuclear pSMAD1/5/8 (Fig. $4 a-$ c). This indicates that ablation of $\beta 1$-integrin increases BMP signaling in migrating EZCs after SCI. To further investigate the extent of interaction between $\beta 1$-integrin and BMP signaling pathways, we examined levels of pSMAD1/5/8 by Western blot analysis in whole-cell lysates prepared from differentiated NSCs. Since BMPRs also signal by activating p38 (Kamiya et al., 2010), we also examined levels of phospho-p38 (pp38). Levels of both pSMAD $1 / 5 / 8$ and pp38 were increased by ablation of $\beta 1$-integrin (Fig. 4d). BMP signaling is known to increase astrocytic lineage commitment by NSCs (Gross et al., 1996) and increases expres- 
a

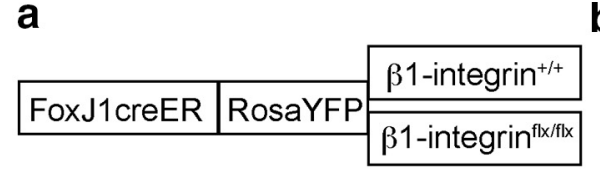

b age

$8 w k$

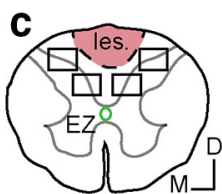

5d Tamoxifen SClsac sac sac

Behavioral Testing
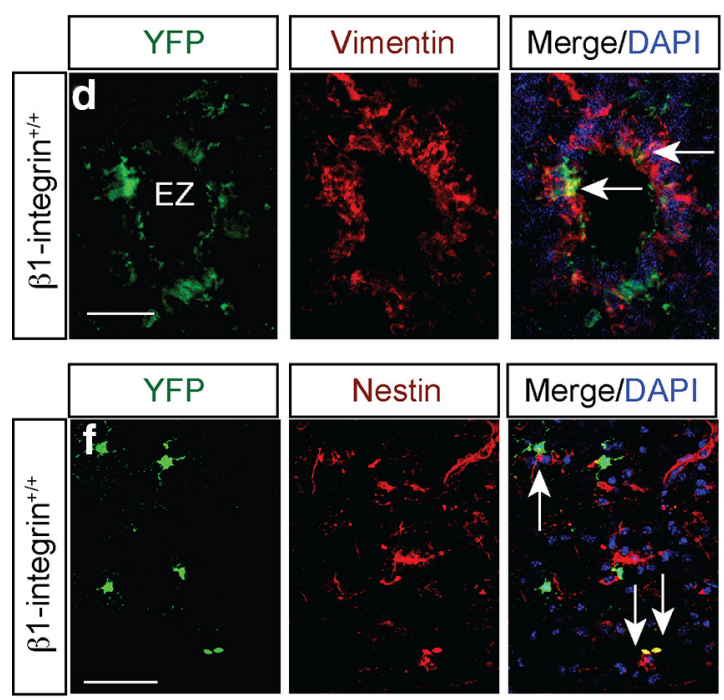
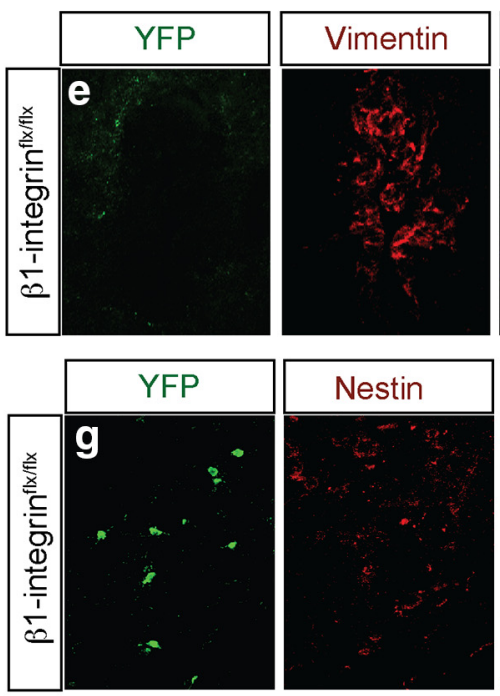

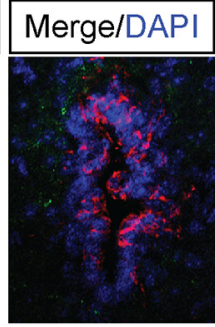

Merge/DAPI

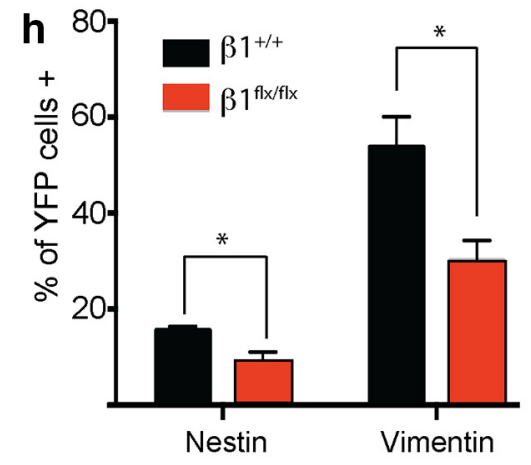

i

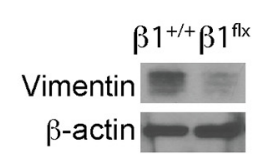

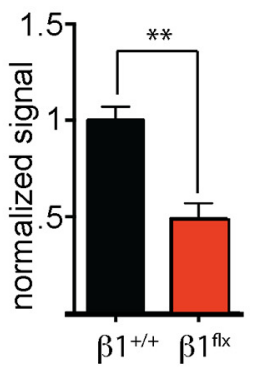
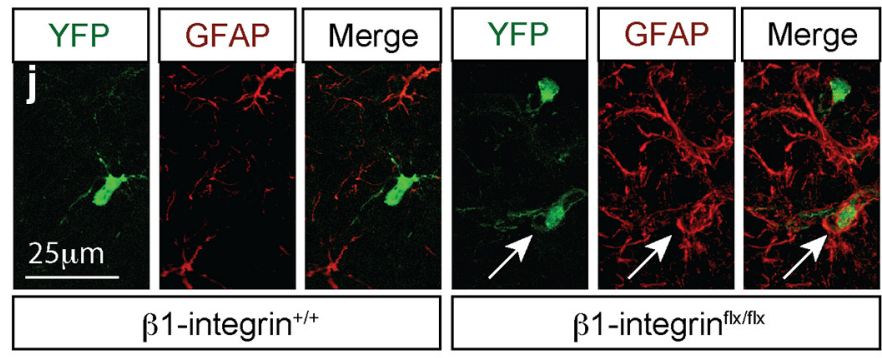

k

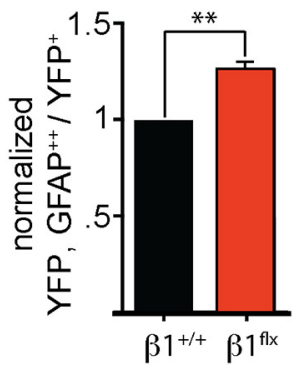

I

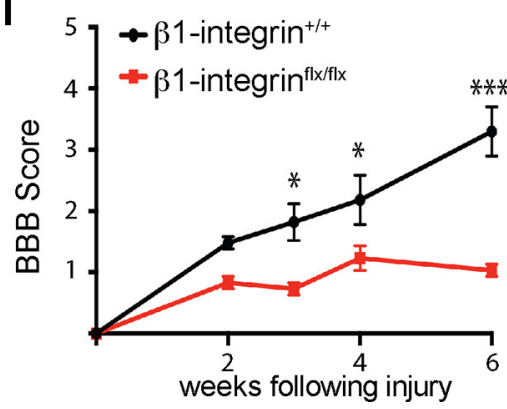

Figure 3. EZC progeny lacking $\beta 1$-integrin express less vimentin and nestin and more GFAP than wild-type cells following SCI. $\boldsymbol{a}-\boldsymbol{c}$, Schematic representation of experimental paradigm. $\boldsymbol{a}$, FoxJ1creER; RosaYFP mice were bred to $\beta 1$-integrin ${ }^{\text {fx/ } /+}$ mice to generate both $\beta 1^{+/+}$and $\beta 1^{\text {flx/flix }}$ littermates. $\boldsymbol{b}$, Eight-week-old FoxJ1creER; RosaYFP $\left(\beta 1^{+/+}\right)$or FoxJ1creER; RosaYFP; $\beta 1$-integrin flx/flx $\left(\beta 1^{f(x / f l}\right)$ mice received tamoxifen to induce recombination in ependymal cells, followed by a clearing period before SCl. Animals were killed (sac) $2 \mathrm{~d}, 1$ week, and 6 weeks following injury. c, Schematic of coronal, thoracic-level spinal cord sections indicating location of dorsal lesion site (les.), EZ (green circle), and boxes demonstrating regions from which images were taken and quantifications generated. $\boldsymbol{d}, \boldsymbol{e}$, YFP (green) and vimentin (red) expression in EZCs 6 weeks postSCl in $\beta 1^{+/+}$(d) and $\beta 1^{\text {flx/ffix }}$ (e) mice. EZCs continue to express vimentin at this time point, but fewer EZCs that had been recombined before injury (green) remained in the EZ in $\beta 1^{\text {flx fffx }}$ animals than in $\beta 1^{+/+} . \boldsymbol{f}, \boldsymbol{g}$, Nestin expression (red) in glial scar regions 6 weeks post SCl in $\beta 1^{+/+}(\boldsymbol{f})$ and $\beta 1^{\text {flxfflx }}(\boldsymbol{g})$ mice show a moderate amount of coexpression of YFP (green), with a significantly lower amount of coexpression in $\beta 1^{\text {flx/flx }}$ than $\beta 1^{+/+}$controls. $\boldsymbol{h}$, Percentage of YFP ${ }^{+}$cells coexpressing nestin (left bars) or vimentin (right bars) in the glial scar region 6 weeks postSCl.i, Western blot analysis of whole-cell lysates from NSCs differentiated in vitro for 1 week shows decrease in vimentin expression in $\beta 1^{\mathrm{fl} / \mathrm{flix}}$ cells. Quantification of three independent trials illustrated in graph to the right. $\boldsymbol{j}, \boldsymbol{k}$, High-magnification images of recombined cells (green) show higher coexpression (arrows) of YFP and GFAP (red), which upon quantification ( $\boldsymbol{k}$ ) was significantly $(p<0.01$ ) different (percentage of recombined cells that also express GFAP; WT figure normalized to 1 for each flight; six flights analyzed). $I$, BBB scoring to measure hindlimb recovery from paralysis revealed $\beta 1^{\text {flx/flix }}$ mice to be significantly $(p<0.001)$ more impaired than $\beta 1^{+/+}$control mice by 6 weeks post SCI. Scale bars: $50 \mu \mathrm{m}$. M, medial; D, dorsal.

sion of GFAP (Bonaguidi et al., 2005; Agius et al., 2010). We also found that ablation of $\beta 1$-integrin markedly increased levels of GFAP expression (Fig. $4 d$ ). The ID proteins are known targets of BMP signaling, and levels of all four members of this family were modestly increased in cells lacking $\beta 1$-integrin (data not shown). These data indicate that ablation of $\beta 1$-integrin in NSCs leads to increased BMP signaling. Having determined this, we also asked whether BMP signaling has a related effect on $\beta 1$-integrin. In- 
triguingly, treatment of NSCs with BMP4 led to an increase in $\beta 1$-integrin expression, suggesting the relationship between $\beta 1$-integrin and BMP signaling may exist to temper one another homeostatically (Fig. $4 e-f^{\prime \prime}$ ).

Because both $\beta 1$-integrin and the BMPRs are cell-surface molecules that can physically complex with other proteins in the cell membrane (Sekiya et al., 2004; Nohe et al., 2005), we next asked whether BMPRs physically interact with $\beta 1$-integrin in NSCs. Coimmunoprecipitation studies revealed that BMPR1a and $1 \mathrm{~b}$ (Fig. $5 a$ ), but not BMPRII or downstream signalers SMAD1/5/8 and p38 (data not shown) interacted with $\beta 1$-integrin in NSCs. The physical interaction between $\beta 1$-integrin and BMPRs $1 \mathrm{a}$ and $1 \mathrm{~b}$ was also detected in adult spinal cord lysates (data not shown). Binding of $\beta 1$-integrin and BMP at the receptor level suggests the inhibitory effect of $\beta 1$-integrin on BMP signaling may be downstream of BMP ligand activity. To investigate this supposition, we asked whether GFAP expression increases in $\beta 1$-integrin-null NSCs even in the presence of the BMP ligand inhibitor noggin. Indeed, $\beta 1$-integrin ablation results in elevated GFAP expression in a ligandindependent manner (Fig. 5b).

We next investigated how this physical interaction might regulate BMP signaling. Cell membranes contain areas of detergent-resistant lipid domains known as lipid rafts. Many molecules have enhanced signaling capability when present in lipid rafts (Decker et al., 2004), and binding to $\beta 1$-integrin can influence the membrane compartment localization of other signaling molecules (Bi et al., 2013; Srikanth et al., 2013; Wang et al., 2013). We therefore examined BMPR expression and localization by Western analyses in both whole-cell lysates and lipid raft fractions isolated from $\beta 1^{+/+}$and $\beta 1^{\mathrm{flx} / \mathrm{flx}}$ NSCs. Total levels of both BMPR1a and $1 \mathrm{~b}$ were slightly decreased in $\beta 1^{\mathrm{flx} / \mathrm{flx}}$ NSCs compared with $\beta 1^{+/+}$NSCs (Fig. $5 c, d)$ despite the significant increase in BMP signaling in these cells (Fig. 4). However, levels of BMPR1b in the lipid raft fractions were markedly increased after ablation of $\beta 1$-integrin ${ }^{+/+}$ (Fig. $5 c, d$ ). This suggested that signaling by BMPRs in the lipid rafts is responsible for the increase in BMP signaling in $\beta 1^{\mathrm{flx} / \mathrm{flx}}$ cells. To determine whether the BMP signaling in NSCs occurs through lipid rafts, we examined the effects of the lipid raftinterrupting drug $\mathrm{M}-\beta$-cyclodextran $(\mathrm{M} \beta \mathrm{CD}$; Klein et al., 1995; Yanagisawa et al., 2004). Treatment with M $\beta C D$ profoundly reduced $\mathrm{PSMAD}$ expression $5 \mathrm{~h}$ after drug exposure (Fig. 5e), and GFAP expression $5 \mathrm{~d}$ after drug exposure (data not shown), indicating that lipid rafts are critical for BMP signaling in NSCs and for the resultant GFAP upregulation. In toto, these observations suggest that $\beta 1$-integrin attenuates GFAP expression by physically interacting with BMPRs in the cell membrane and limiting their ability to move into lipid rafts and signal.
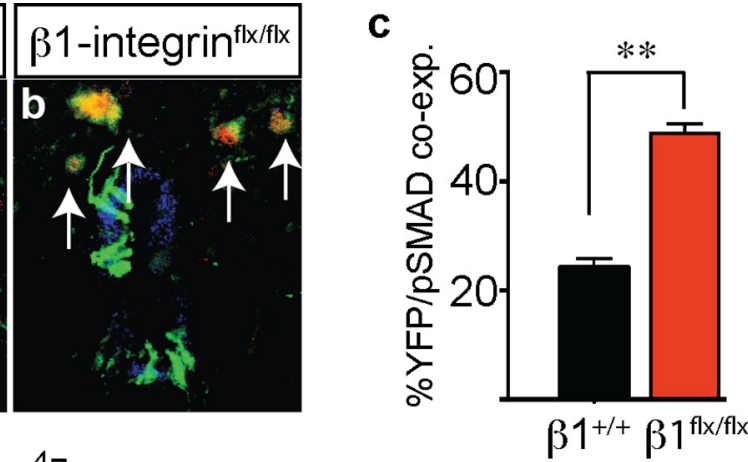

e
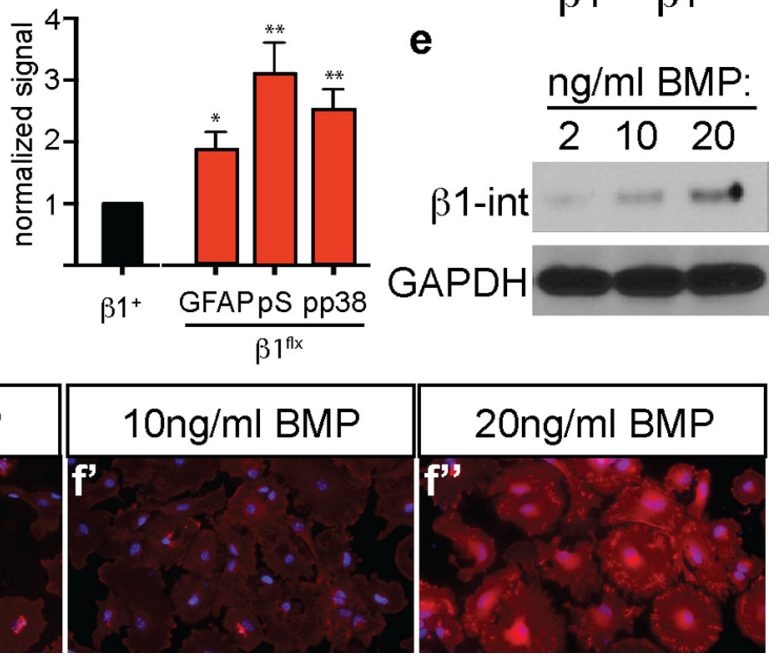

Figure 4. $\quad \beta 1$-integrin signaling and BMP signaling oppose one another in differentiating NSCs. $\boldsymbol{a}-\boldsymbol{c}$, Recombined EZCs (green) in $\beta 1^{+{ }^{+}}(\boldsymbol{a})$ and $\beta 1^{\mathrm{flx} / f \mathrm{fl}}(\boldsymbol{b})$ animals are detected both in the EZ and migrating away from the EZ at $2 \mathrm{~d}$ post SCl. pSMAD ${ }^{+}$cells (red) are detected near the EZ in both genotypes, but coexpression of YFP and pSMAD is significantly $(p<0.01)$ greater in $\beta 1^{\mathrm{flx} / f \mathrm{l} x}$

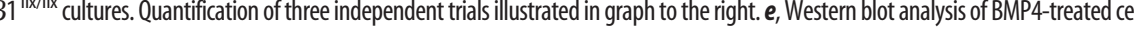
列 $\mathrm{ng} / \mathrm{ml}$ throughout differentiation. $\boldsymbol{f}$, DAPI (blue) and $\beta 1$-integrin expression (red) in differentiated SVZ-derived NSCs under increasing BMP4 media concentrations. Scale bars: $50 \mu \mathrm{m}$.

\section{Discussion}

Injury to the spinal cord resulted in a marked increase in expression of $\beta 1$-integrin by EZCs. Ablation of $\beta 1$-integrin from these cells decreased stem cell markers in progeny and increased their GFAP expression and astrocytic differentiation. The increased astrogliosis appeared to be mediated by increased partitioning of BMPR1b into the lipid raft fraction of the cell membrane with a resultant increase in BMP signaling. We conclude that $\beta 1$ integrin expression by EZCs after SCI regulates the generation of GFAP-expressing astrocytes, and that $\beta 1$-integrin directly interacts with BMP receptors, an interaction that may be responsible for its ability to limit the known deleterious effects of BMPR1b signaling on the formation of the glial scar.

\section{$\beta 1$-integrin expression by EZCs limits astrocyte generation} and helps to maintain the stem/progenitor cell state

Our findings both in culture and in vivo indicate that $\beta 1$-integrin helps to maintain the stem cell state of EZCs and to limit astrocyte differentiation. We found similar effects of $\beta 1$-integrin in SVZderived NSCs. These observations agree well with prior observations of the developing nervous system, in which integrins have been shown to play multiple roles (Milner and Campbell, 2002). $\beta 1$-integrin is highly expressed by NSCs and in fact has been used as a cell-surface marker for NSC enrichment (Hall et al., 2006; Pruszak et al., 2009). $\beta 1$-integrin regulates both the survival and 
a

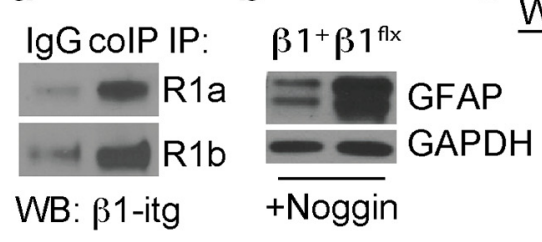

Whole NSC lysates: Lipid raft fractions:
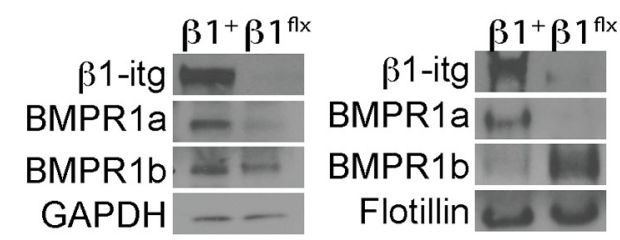

d

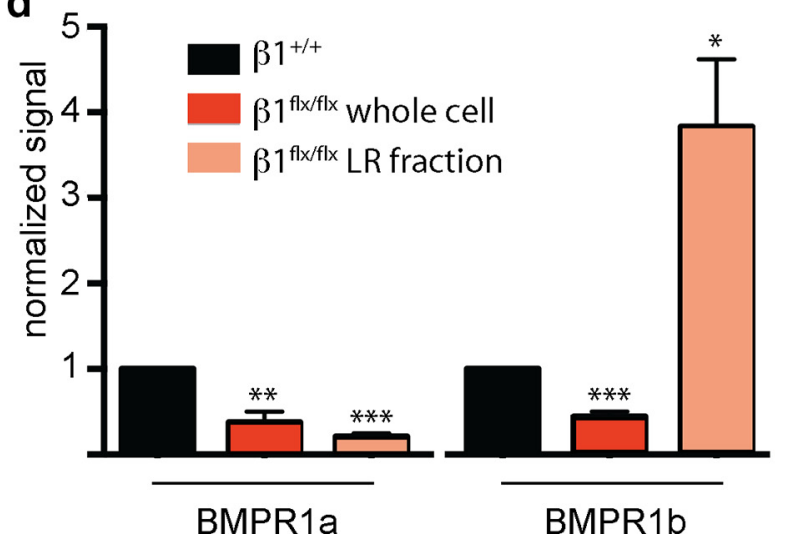

Figure 5. $\quad \beta 1$-integrin tempers BMPR signaling through physical interaction and exclusion from lipid raft signaling fractions. $\boldsymbol{a}$, Coimmunoprecipitation of BMPR1a and $1 \mathrm{~b}$ and immunoblotting for $\beta 1$-integrin reveals a physical interaction between the type 1 receptor subunits. $\boldsymbol{b}$, Differentiated NSC GFAP increases in the absence of $\beta 1$-integrin even in the presence of the BMP inhibitor Noggin. $c$, Left, Western blot analyses of whole-cell lysates of SVZ-derived NSCs demonstrate that expression levels of BMPR1a and $1 \mathrm{~b}$ are decreased in $\beta 1^{\text {flxfflx }}$ cultures. Right, Western blot analyses of lipid raft (LR) fractions isolated from SVZ-derived NSCS demonstrate that while BMPR1a is decreased in $\beta 1^{\mathrm{fl} / f \mathrm{fl} x} \mathrm{LRs}$, to a degree reflective of expression in the whole cells $(\boldsymbol{b}), \mathrm{BMPR} 1 \mathrm{~b}$ is markedly increased in the LR fraction of $\beta 1^{\mathrm{fl} / \mathrm{flf} x}$ cells. $\boldsymbol{d}$, Quantification of representative Western blot signals (c) from multiple independent trials illustrated graphically. $\mathbf{e}$, Disruption of lipid rafts by $M \beta C D$ treatment diminishes BMP signaling through pSMADs. Quantification of pSMAD signal from multiple independent trials illustrated in graph below. Veh, vehicle.

$\beta 1$-integrin expression and signaling in EZCs might be beneficial therapeutically.

\section{Interaction of $\boldsymbol{\beta} 1$-integrin with BMP receptors regulates GFAP expression} We next focused on identifying the molecular mechanisms underlying the effects of $\beta 1$-integrin on astrocytic differentiation. Previous studies have shown that astrocytic lineage commitment both by SVZ NSCs (Gross et al., 1996) and by glial restricted progenitor cells (Mabie et al., 1997; Cheng et al., 2007) is regulated by BMP signaling. BMP levels increase following spinal cord injury (Setoguchi et al., 2001; Chen et al., 2005), and this increase may in fact lead to the observed increase in $\beta 1$-integrin expression in the injured spinal cord: we found that treatment of NSCs in vitro with BMP4 increased $\beta 1$ integrin expression in a dose-dependent manner (Fig. $4 e-f^{\prime}$ ). It is possible that $\beta 1$ integrin increases in response to elevated BMP in a homeostatic manner; elevated BMP signaling would be attenuated by a subsequent increase in $\beta 1$-integrin, and the BMP effect on the cell would therefore be tempered. Regardless of whether it causes the observed upregulation of $\beta 1$ integrin in vivo, BMP signaling appears to contribute to both the beneficial and the deleterious effects of gliosis after SCI (Setoguchi et al., 2004; Enzmann et al., 2005; Matsuura et al., 2008; Sahni et al.,

proliferation of NSCs in response to cues from the extracellular matrix (Leone et al., 2005). Higher levels of $\beta 1$-integrin expression by cultured NSCs correlate with a higher capability for selfrenewal mediated via the MAPK cascade (Campos et al., 2004). $\beta 1$-integrin signaling has been shown to limit astrocyte differentiation from NSCs (Pan et al., 2014), as well as influence the morphology of mature astrocytes, their polarity and gene expression, including GFAP expression, but not proliferation (Peng et al., 2008; Robel et al., 2009). Our observation that $\beta 1$-integrin signaling limits the generation of astrocytes by EZCs after spinal cord injury suggests the signaling system as a potential therapeutic target for limiting glial scar formation after SCI.

Therapeutic strategies to modify astrogliosis and to limit the detrimental effects of glial scar formation after SCI must accomplish this while still preserving the beneficial effects of astrogliosis (Faulkner et al., 2004; Sofroniew, 2005; Okada et al., 2006; Herrmann et al., 2008). EZC progeny exert beneficial effects on recovery from SCI (Sabelström et al., 2013), but they also contribute approximately half of the new astrocytes that are generated after SCI and contribute to the cells that constitute the glial scar (Barnabé-Heider et al., 2010). Our observations suggest that $\beta 1$ integrin expression by EZCs helps to maintain the beneficial effects of the progeny while limiting the detrimental effects. Specifically, we found that ablation of $\beta 1$-integrin from EZCs profoundly worsened functional recovery after SCI. Our data suggest that the loss of $\beta 1$-integrin increases expression of GFAP in ependymal-derived NSCs migrating toward the injury site and accelerates their differentiation into astrocytes that are harmful to functional recovery. This raises the possibility that enhancing
2010). More specifically, signaling by the BMPR1b subunit mediates deleterious effects of BMP signaling after SCI whereas signaling by the BMPRla subunit mediates beneficial effects (Sahni et al., 2010). The effects of ablation of $\beta 1$-integrin following SCI mirrored the effects of activated BMPR1b signaling, consistent with our observation that BMP signaling (pSMAD1/5/8, pp38) increases in EZC progeny both in vivo and in culture when $\beta 1$ integrin is absent. These findings suggest that the presence of $\beta 1$-integrin in the cell membrane inhibits BMP signaling in the cell. Furthermore, the increase in GFAP resulting from $\beta 1$ integrin loss occurred even in the presence of the BMP ligand inhibitor noggin (Fig. $5 b$ ), suggesting $\beta 1$-integrin's effect on $\mathrm{BMP}$ signaling is independent of BMP ligand presence. This raised the possibility that $\beta 1$-integrin directly interacts with $\mathrm{BM}$ PRs to modify their signaling. Indeed, coimmunoprecipitation assays demonstrated complexing between $\beta 1$-integrin and the BMP type 1 receptor subunits in both NSCs differentiating in vitro and in adult whole spinal cord lysates.

There are a number of possible mechanisms that could explain how this physical interaction attenuates BMP signaling. Caveolin binding to BMPRII has been shown to inhibit the interaction of RII with R1a, inhibiting BMP signaling (Nohe et al., 2005). During Xenopus neural induction, BMP receptor activation is curtailed by direct interaction with Dullard, which colocalizes BMPRs to caveolin, where they are degraded (Satow et al., $2006)$. In the case of $\beta 1$-integrin loss, however, the overall expression levels of BMPR1a and R1b were diminished, not increased, as would be the case if $\beta 1$-integrin normally contributed to their degradation. Alternatively, there are many examples of integrin 
and growth receptor cross talk that regulate cell proliferation, differentiation, and migration (Ivaska and Heino, 2011). In a prior study, we found that $\beta 1$-integrin altered the localization of EGFRs within lipid rafts in glioblastoma stem cells, and that this altered EGFR signaling (Srikanth et al., 2013). A shift in BMPR localization to portions of the cell membrane that are more conducive to their signal transduction could explain the elevation in BMP signaling despite the observed decrease in receptor expression in cells lacking $\beta 1$-integrin. Indeed, our finding that ablation of $\beta 1$-integrin leads to preferential partitioning of BMPR1b into lipid rafts with a concurrent increase in BMP signaling suggests that the presence of $\beta 1$-integrin inhibits BMPR1b-mediated signaling by preventing its localization into the lipid raft. Despite the increase in BMP signaling, the total level of BMPR expression appeared to decrease. This is similar to what has been observed in interactions between $\beta 1$-integrin and other receptors, such as PDGFR, which cause a change in the signaling propensity of that receptor opposite to the resulting change of expression (Zemskov et al., 2009). It is therefore not unprecedented that a receptor may experience a change in its signaling strength due to an interaction with $\beta 1$-integrin, regardless of the receptor's expression level.

In summary, expression of $\beta 1$-integrin by EZCs after SCI is a beneficial response that both enhances the migration of EZC progeny into the area of injury where the cells facilitate recovery (Sabelström et al., 2013) and limits differentiation of the cells into GFAP-expressing astrocytes, while restricting the entry of BMPR1b into lipid rafts. These studies highlight the importance of $\beta 1$-integrin in the regulation of astrogliosis, and suggest $\beta 1$ integrin as a potential target for therapeutic intervention for SCI.

\section{References}

Agius E, Decker Y, Soukkarieh C, Soula C, Cochard P (2010) Role of BMPs in controlling the spatial and temporal origin of GFAP astrocytes in the embryonic spinal cord. Dev Biol 344:611-620. CrossRef Medline

Barnabé-Heider F, Frisén J (2008) Stem cells for spinal cord repair. Cell Stem Cell 3:16-24. CrossRef Medline

Barnabé-Heider F, Göritz C, Sabelström H, Takebayashi H, Pfrieger FW, Meletis K, Frisén J (2010) Origin of new glial cells in intact and injured adult spinal cord. Cell Stem Cell 7:470-482. CrossRef Medline

Bi J, Wang R, Zhang Y, Han X, Ampah KK, Liu W, Zeng X (2013) Identification of nucleolin as a lipid-raft-dependent betal-integrin-interacting protein in A375 cell migration. Mol Cells 36:507-517. CrossRef Medline

Bonaguidi MA, McGuire T, Hu M, Kan L, Samanta J, Kessler JA (2005) LIF and BMP signaling generate separate and discrete types of GFAPexpressing cells. Development 132:5503-5514. CrossRef Medline

Campos LS, Leone DP, Relvas JB, Brakebusch C, Fässler R, Suter U, ffrenchConstant C (2004) Betal integrins activate a MAPK signalling pathway in neural stem cells that contributes to their maintenance. Development 131:3433-3444. CrossRef Medline

Chen J, Leong SY, Schachner M (2005) Differential expression of cell fate determinants in neurons and glial cells of adult mouse spinal cord after compression injury. Eur J Neurosci 22:1895-1906. CrossRef Medline

Cheng X, Wang Y, He Q, Qiu M, Whittemore SR, Cao Q (2007) Bone morphogenetic protein signaling and olig1/2 interact to regulate the differentiation and maturation of adult oligodendrocyte precursor cells. Stem Cells 25:3204-3214. CrossRef Medline

Decker L, Baron W, ffrench-Constant C (2004) Lipid rafts: microenvironments for integrin-growth factor interactions in neural development. Biochem Soc Trans 32:426-430. CrossRef Medline

Enzmann GU, Benton RL, Woock JP, Howard RM, Tsoulfas P, Whittemore SR (2005) Consequences of noggin expression by neural stem, glial, and neuronal precursor cells engrafted into the injured spinal cord. Exp Neurol 195:293-304. CrossRef Medline

Faulkner JR, Herrmann JE, Woo MJ, Tansey KE, Doan NB, Sofroniew MV (2004) Reactive astrocytes protect tissue and preserve function after spinal cord injury. J Neurosci 24:2143-2155. CrossRef Medline

Fawcett JW, Asher RA (1999) The glial scar and central nervous system repair. Brain Res Bull 49:377-391. CrossRef Medline
Fuller ML, DeChant AK, Rothstein B, Caprariello A, Wang R, Hall AK, Miller RH (2007) Bone morphogenetic proteins promote gliosis in demyelinating spinal cord lesions. Ann Neurol 62:288-300. CrossRef Medline

Gross RE, Mehler MF, Mabie PC, Zang Z, Santschi L, Kessler JA (1996) Bone morphogenetic proteins promote astroglial lineage commitment by mammalian subventricular zone progenitor cells. Neuron 17:595-606. CrossRef Medline

Hall PE, Lathia JD, Miller NG, Caldwell MA, ffrench-Constant C (2006) Integrins are markers of human neural stem cells. Stem Cells 24:2078 2084. CrossRef Medline

Heldin CH, Miyazono K, ten Dijke P (1997) TGF-beta signalling from cell membrane to nucleus through SMAD proteins. Nature 390:465-471. CrossRef Medline

Herrmann JE, Imura T, Song B, Qi J, Ao Y, Nguyen TK, Korsak RA, Takeda K, Akira S, Sofroniew MV (2008) STAT3 is a critical regulator of astrogliosis and scar formation after spinal cord injury. J Neurosci 28:7231-7243. CrossRef Medline

Ivaska J, Heino J (2011) Cooperation between integrins and growth factor receptors in signaling and endocytosis. Annu Rev Cell Dev Biol 27:291320. CrossRef Medline

Joshi M, Fehlings MG (2002) Development and characterization of a novel, graded model of clip compressive spinal cord injury in the mouse: Part 1. Clip design, behavioral outcomes, and histopathology. J Neurotrauma 19:175-190. CrossRef Medline

Kamiya N, Kobayashi T, Mochida Y, Yu PB, Yamauchi M, Kronenberg HM, Mishina Y (2010) Wnt inhibitors Dkk1 and Sost are downstream targets of BMP signaling through the type IA receptor (BMPRIA) in osteoblasts. J Bone Miner Res 25:200-210. CrossRef Medline

Kazanis I, ffrench-Constant C (2011) Extracellular matrix and the neural stem cell niche. Dev Neurobiol 71:1006-1017. CrossRef Medline

Klein U, Gimpl G, Fahrenholz F (1995) Alteration of the myometrial plasma membrane cholesterol content with beta-cyclodextrin modulates the binding affinity of the oxytocin receptor. Biochemistry 34:13784-13793. CrossRef Medline

Leone DP, Relvas JB, Campos LS, Hemmi S, Brakebusch C, Fässler R, ffrenchConstant C, Suter U (2005) Regulation of neural progenitor proliferation and survival by betal integrins. J Cell Sci 118:2589-2599. CrossRef Medline

Mabie PC, Mehler MF, Marmur R, Papavasiliou A, Song Q, Kessler JA (1997) Bone morphogenetic proteins induce astroglial differentiation of oligodendroglial-astroglial progenitor cells. J Neurosci 17:4112-4120. Medline

Matsuura I, Taniguchi J, Hata K, Saeki N, Yamashita T (2008) BMP inhibition enhances axonal growth and functional recovery after spinal cord injury. J Neurochem 105:1471-1479. CrossRef Medline

McGraw J, Hiebert GW, Steeves JD (2001) Modulating astrogliosis after neurotrauma. J Neurosci Res 63:109-115. CrossRef Medline

Mehler MF, Mabie PC, Zhu G, Gokhan S, Kessler JA (2000) Developmental changes in progenitor cell responsiveness to bone morphogenetic proteins differentially modulate progressive CNS lineage fate. Dev Neurosci 22:74-85. CrossRef Medline

Meletis K, Barnabé-Heider F, Carlén M, Evergren E, Tomilin N, Shupliakov O, Frisén J (2008) Spinal cord injury reveals multilineage differentiation of ependymal cells. PLoS Biol 6:e182. CrossRef Medline

Milner R, Campbell IL (2002) The integrin family of cell adhesion molecules has multiple functions within the CNS. J Neurosci Res 69:286-291. CrossRef Medline

Munger JS, Sheppard D (2011) Cross talk among TGF-beta signaling pathways, integrins, and the extracellular matrix. Cold Spring Harb Perspect Biol 3:a005017. CrossRef Medline

Nohe A, Keating E, Underhill TM, Knaus P, Petersen NO (2005) Dynamics and interaction of caveolin-1 isoforms with BMP-receptors. J Cell Sci 118:643-650. CrossRef Medline

Okada S, Nakamura M, Katoh H, Miyao T, Shimazaki T, Ishii K, Yamane J, Yoshimura A, Iwamoto Y, Toyama Y, Okano H (2006) Conditional ablation of Stat 3 or Socs 3 discloses a dual role for reactive astrocytes after spinal cord injury. Nat Med 12:829-834. CrossRef Medline

Pan L, North HA, Sahni V, Jeong SJ, Mcguire TL, Berns EJ, Stupp SI, Kessler JA (2014) Betal-integrin and integrin linked kinase regulate astrocytic differentiation of neural stem cells. PLoS One 9:e104335. CrossRef Medline

Peng H, Shah W, Holland P, Carbonetto S (2008) Integrins and dystrogly- 
can regulate astrocyte wound healing: the integrin beta1 subunit is necessary for process extension and orienting the microtubular network. Dev Neurobiol 68:559-574. CrossRef Medline

Pruszak J, Ludwig W, Blak A, Alavian K, Isacson O (2009) CD15, CD24, and CD29 define a surface biomarker code for neural lineage differentiation of stem cells. Stem Cells 27:2928-2940. CrossRef Medline

Rawlins EL, Ostrowski LE, Randell SH, Hogan BL (2007) Lung development and repair: contribution of the ciliated lineage. Proc Natl Acad Sci U S A 104:410-417. CrossRef Medline

Robel S, Mori T, Zoubaa S, Schlegel J, Sirko S, Faissner A, Goebbels S, Dimou L, Götz M (2009) Conditional deletion of betal-integrin in astroglia causes partial reactive gliosis. Glia 57:1630-1647. CrossRef Medline

Sabelström H, Stenudd M, Réu P, Dias DO, Elfineh M, Zdunek S, Damberg P, Göritz C, Frisén J (2013) Resident neural stem cells restrict tissue damage and neuronal loss after spinal cord injury in mice. Science 342:637640. CrossRef Medline

Sahni V, Mukhopadhyay A, Tysseling V, Hebert A, Birch D, Mcguire TL, Stupp SI, Kessler JA (2010) BMPR1a and BMPR1b signaling exert opposing effects on gliosis after spinal cord injury. J Neurosci 30:1839-1855. CrossRef Medline

Satow R, Kurisaki A, Chan TC, Hamazaki TS, Asashima M (2006) Dullard promotes degradation and dephosphorylation of BMP receptors and is required for neural induction. Dev Cell 11:763-774. CrossRef Medline

Sekiya T, Adachi S, Kohu K, Yamada T, Higuchi O, Furukawa Y, Nakamura Y, Nakamura T, Tashiro K, Kuhara S, Ohwada S, Akiyama T (2004) Identification of BMP and activin membrane-bound inhibitor (BAMBI), an inhibitor of transforming growth factor-beta signaling, as a target of the beta-catenin pathway in colorectal tumor cells. J Biol Chem 279:68406846. CrossRef Medline
Setoguchi T, Yone K, Matsuoka E, Takenouchi H, Nakashima K, Sakou T, Komiya S, Izumo S (2001) Traumatic injury-induced BMP7 expression in the adult rat spinal cord. Brain Res 921:219-225. CrossRef Medline

Setoguchi T, Nakashima K, Takizawa T, Yanagisawa M, Ochiai W, Okabe M, Yone K, Komiya S, Taga T (2004) Treatment of spinal cord injury by transplantation of fetal neural precursor cells engineered to express BMP inhibitor. Exp Neurol 189:33-44. CrossRef Medline

Silver J, Miller JH (2004) Regeneration beyond the glial scar. Nat Rev Neurosci 5:146-156. CrossRef Medline

Sofroniew MV (2005) Reactive astrocytes in neural repair and protection. Neuroscientist 11:400-407. CrossRef Medline

Srikanth M, Das S, Berns EJ, Kim J, Stupp SI, Kessler JA (2013) Nanofibermediated inhibition of focal adhesion kinase sensitizes glioma stemlike cells to epidermal growth factor receptor inhibition. Neuro Oncol 15: 319-329. CrossRef Medline

Wang R, Bi J, Ampah KK, Zhang C, Li Z, Jiao Y, Wang X, Ba X, Zeng X (2013) Lipid raft regulates the initial spreading of melanoma A375 cells by modulating beta1 integrin clustering. Int J Biochem Cell Biol 45:1679-1689. CrossRef Medline

Wipff PJ, Hinz B (2008) Integrins and the activation of latent transforming growth factor betal-an intimate relationship. Eur J Cell Biol 87:601-615. CrossRef Medline

Yanagisawa M, Nakamura K, Taga T (2004) Roles of lipid rafts in integrindependent adhesion and gp130 signalling pathway in mouse embryonic neural precursor cells. Genes Cells 9:801-809. CrossRef Medline

Zemskov EA, Loukinova E, Mikhailenko I, Coleman RA, Strickland DK, Belkin AM (2009) Regulation of platelet-derived growth factor receptor function by integrin-associated cell surface transglutaminase. J Biol Chem 284:16693-16703. CrossRef Medline 